\title{
Tagarelices sobre o desassossego da obra orteguiana
}

Norma Côrtes

ORTEGA Y GASSET, José. Obras Completas (1949-1955). Tomo X, Obra póstuma e Índices. Madrid: Fundación Ortega y Gasset, Editorial Taurus, 2010, $1.296 \mathrm{p}$.

Há 27 anos, o atual presidente do Instituto Histórico e Geográfico Brasileiro (IHGB), o professor Arno Wehling, publicou uma pequena, mas aguda, nota crítica a propósito do lançamento da segunda edição das Obras Completas de José Ortega y Gasset (1883 - 1955). No ano anterior (1983), em Madri, a Alianza Editorial havia concluído a reedição em 12 volumes dos escritos orteguianos cuja primeiríssima compilação fora iniciada ainda em 1932, pela Espasa-Calpe. ${ }^{1}$ Intitulada Ortega e uma nova ciência do homem: o conhecimento histórico, a nota crítica de Wehling assinalou a novidade trazida pela recém-lançada publicação da Alianza Editorial. E principalmente salientou que alguns dos seus inéditos, notadamente os de teoria da razão histórica, permitiriam uma significativa reavaliação do quilate intelectual de Ortega, uma vez que o conjunto do seu pensamento projetava-se então para além da sombra consagradora, porém demasiadamente forte, de La rebelión de las masas (1930) - o livro de maior sucesso do filósofo espanhol. Wehling vaticinava com razão: a segunda edição das Obras Completas foi realmente expressiva de um rearranjo intelectual e acelerou o impulso de uma inflexão na fortuna crítica da obra de José Ortega y Gasset.

Como é frequente nos grandes pensadores, as ideias orteguianas têm sido continuamente atualizadas por meio de sucessivos esforços geracionais cujas vogas críticas resultaram em metamorfoses e desacordos interpretativos. Para uns, conservador; para outros, o contrário: modernista e liberal; Ortega não apenas foi variegadamente compreendido sob quase todo o espectro de colorações das ideias sociais e políticas como também foi, ora vestido com a toga da seriedade do filósofo, ora, depreciado como mero publicista e cronista de ocasião.
A multiplicidade dessas perspectivas não tem encontrado sossego e foi ampliada por muitas razóes. Primeiro, porque a história da recepção de sua obra realmente se confundiu tanto com as controvérsias provocadas por sua figura pública (quando ele ainda era vivo) quanto com as vicissitudes da vida política e cultural da Espanha durante todo o perturbado século XX (e isso envolveu a diáspora da inteligência hispânica com a consequente difusão do pensamento orteguiano, especialmente nos países da América ibérica) além, é claro, de todos esses ecos terem sido constantemente realimentados à medida que as sucessivas edições dos seus livros foram republicadas. E, segundo, porque sua obra foi mesmo de circunstância. Ou melhor, não que sua inteligência fosse casuística, dada ao sabor da ocasião, mas sim porque era autêntica a máxima "Yo soy yo y mi circunstancia". Intérprete atento dos acontecimentos, Ortega soube dar loquacidade à chamada geração de 1914 traduzindo com erudição filosófica as perplexidades de um império decaído e os dilemas de modernização de uma península invertebrada, com rincôes regionalistas, além de eivada pelos murmúrios de uma tradição limítrofe às fronteiras (da racionalidade) do Ocidente. Contrário ao dogmatismo do racionalismo voluntarista, que imagina alcançar o futuro por meio dos cálculos consensuais da razão, mas simultaneamente crítico à fuga tradicionalista que habita no imaginário de um passado de fúrias, seu pensamento consistia numa obstinada tentativa para dissolver antagonismos irreconciliáveis. Por conseguinte, mas desagradando a ambos os polos, ele tentou superar dualismos conceituais ossificados e rejeitou opor a consciência ao mundo; o eu à sua circunstância; a razão à história; o conhecimento ao acontecimento; a ciência à consciência; a vida ativa à contemplação, a criação artística à realidade; o palco à plateia; o sério ao lúdico; o desporte ao Estado, o real ao imaginário etc. Em suma, seus esforços teóricos visaram alcançar uma metafísica capaz de superar 
as clássicas dicotomias entre objetividade e subjetividade; materialismo e idealismo; racionalismo e historicismo etc. E resultaram numa composição ensaística bastante desordenada, embora marcada pela consistente perseguição de terceiro caminho teórico, que (no limite) tangenciou os encantos do irracionalismo desprezando os fundamentos de certeza mantidos por todas as filosofias da consciência e foi encontrar no mundo ordinário - isto é, na vida ou na razão histórica - o princípio de inteligibilidade de todos os seres e haveres do mundo, de tudo o que é e existe.

A tudo isso se acrescenta mais uma razão para o desassossego da fortuna critica de sua obra. Porque, em verdade, ela resiste à classificação sendo demasiadamente assistemática, múltipla e inconclusa (mas grávida de insights saborosamente seminais) para caber numa única chave explicativa. Ensaísta virtuoso, Ortega escrevia com exuberância e fartura. Quer dizer, ele escrevia muito bem e sobre temas demais: artes plásticas, ciências da natureza e humanas, educação, amor e enamoramento, narrativas históricas e ficcionais, técnica e tecnologia, biografias, poesia e poetas, esporte e laser, matemática, biblioteconomia, literatura e romances, touradas, psicologia, teatro, vida e teoria política, universidade etc. etc. O problema é que seu pensamento continha uma virtude desconcertante, pois apesar de ele exibir rara elegância para erguer e provocar desafios teóricos agudos, nunca os resolvia satisfatória ou suficientemente. Seus escritos, portanto, se nos aparecem como fragmentos luminosos, que compõem um mosaico caótico cuja inacababilidade (temática) se duplica e repousa num estado de permanente imprecisão ou irresolução (teórica).

Para além dos antagonismos políticos, não é difícil compreender a hostilidade das gerações de estudiosos que se lhe seguiram. Não obstante o cariz metafísico, o ensaísmo inconcludente de seus textos reverberado por tal profusão temática encontrou baixa aceitação junto às inclinações sistêmicas e cientificistas do estruturalismo, do neopositivismo lógico ou do marxismo. Nas últimas décadas, porém, como as observações de Wehling assinalaram certeiramente, o tônus da recepção ao pensar orteguiano foi alterado e uma reavaliação desapaixonada e compreensiva acerca da importância histórica e do alcance filosófico de suas ideias vem crescentemente ganhando corpo.

Agora, de par com esse ambiente mais benfazejo, novamente se reacende a inquietude na recepção às suas ideias. Em novembro de 2010, veio a público o décimo e último tomo da mais nova, e quiçá definitiva (!), Obras Completas de José Ortega y Gasset. Completíssimos, os dez grandes tomos dessa terceira reedição vêm sendo lançados, desde outubro de 2004, pela Editorial Taurus que, sob a impecável coordenação da equipe de pesquisadores da Fundación Ortega y Gasset, executou um dos mais bem acabados empreendimentos editoriais da atualidade. De primeira, os livros atiçam a nossa cobiça e provocam agradável fruição estética. Afora suas evidentes qualidades gráficas (dimensão dos volumes, encadernação cartonada, gramatura do papel, mancha textual etc.), as sobrecapas e lombadas são alternadas em branco $\&$ preto e mantêm um sutil equilíbrio entre seriedade e jogo sugerindo o grafismo sóbrio, elegante e lúdico de um tabuleiro de xadrez. Além disso, nelas aparecem diferentes e sucessivas fotografias do filósofo. Organizadas cronologicamente, tal conjunto de imagens dá-se como um espelho de figuras continuamente errantes nas quais ele modulou a sua própria auctoritas. Do jovem altivo - cuja pose hierática afetava esnobe erudição - até o rosto calvo, sereno e maliciosamente risonho, mas vincado pelas dobras da maturidade, a terceira reedição das Obras Completas de José Ortega y Gasset exibe primorosos cuidados pré-textuais, que visaram fixar e manter a perenidade (material e intelectual) dos escritos orteguianos e conseguiram atingir um notável grau de fidedignidade histórica entre vida e obra.

Não convém banalizar, naturalizando, tais virtudes editoriais. Porque a disposição temporal do corpus ideográfico de Ortega foi uma opção orientada, rigorosamente compatível com o núcleo pulsante que arde no interior do seu pensamento. Embora as iniciativas anteriores também tenham obedecido à ordem cronológica, a terceira reedição das Obras Completas distingue-se das demais tanto pela acuidade da precisão textual - seu aparato crítico fixa as disparidades entre as várias for- 
mulações de um mesmo escrito corrigindo antigas imprecisões - quanto porque consolida a integralidade da obra orteguiana exibindo, simultaneamente, o desenvolvimento e a historicidade dos esforços envolvidos em sua produção intelectual. À exceção do epistolário, notas de revisão e entrevistas (gêneros que não foram incluídos nessa publicação), todos os demais textos do pensador espanhol estão publicados ao longo dos dez tomos das Obras Completas; cujos quatro últimos tomos são dedicados exclusivamente aos escritos só conhecidos postumamente. Com efeito, o escopo literário dessa reedição alcança desde raridades bibliográficas, tal como a sua tese de doutoramento intitulada Los terrores del año mil. Crítica de una leyenda (1909); passando por uma miríade de outros escritos (artigos, prólogos, apontamentos esparsos etc.) ou inéditos ou já publicados; além de papéis de caráter acroamático, tais como lições de aula ou conferências; até finalmente chegar aos livros consagrados, fartamente conhecidos pelo público, dentre os quais se podem destacar Meditaciones del Quijote (1914), España invertebrada (1922), Ideas y Creencias (1940) entre outros...

Com pleno êxito, o décimo tomo dá o arremate final às Obras Completas. Ele reúne os textos que o "último Ortega" escreveu durante os anos 1949 e 1955, mas não chegou a publicar em vida. Esse foi um período de maturidade, intensa atividade intelectual e de reconhecimento internacional. $\mathrm{E}$ todos esses traços aparecem nos escritos desse último tomo, evidenciando-se, por exemplo, na conferência De Europa meditatio quaedam (1949), que foi proferida em Berlin onde ele reafirmou o seu europeísmo e os fundamentos da cultura europeia (apesar e) diante do esfacelamento do pós-guerra. Finalmente, o tomo também possui um importante Índice Geral cujas mais de quinhentas páginas detalham os seguintes itens: Cronología del corpus textual; Indice alfabético de títulos; Indice de conceptos, onomástico y toponimico. Inexistentes nas antigas edições, tais índices agregam novo valor à publicação, convertendo-a, por um lado, num imprescindível instrumento de trabalho para os pesquisadores, mas, por outro lado também, num manual (espécie de vade mécum), que garante ligeira e fácil acessibilidade para o leitor em geral.
A obra orteguiana está em desassossego. E, para a nossa sorte, o término da reedição de suas Obras Completas encerra a promessa de que outras e novas tagarelices conservarão essa salutar intranquilidade.

\section{Nota}

${ }^{1} \mathrm{Na}$ Madri de 1932, a Espasa-Calpe organizou a primeira compilação dos escritos orteguianos, reunindo os seus principais livros num único volume de 1.410 páginas. Em 1936, outra compilação foi lançada em dois volumes, acrescida de novos textos. Anos mais tarde, em 1943, veio a público a terceira edição desses dois volumes, aos quais se acrescentaram outros dois novos escritos. Entre 1946 e 1947, consolidando tais antologias, teve início a publicação das primeiras Obras Completas, editadas pela Revista de Occidente em seis volumes. Depois da morte de Ortega (1955), houve várias reimpressões dessa mesma edição da Revista de Occidente - que, então, parecia ser a definitiva. Em 1961, novas obras se agregaram ao corpus documental orteguiano e um sétimo volume foi publicado; no ano seguinte, também saíram os volumes 8 e 9 . E em 1969, outros volumes, o 10 e o 11, foram lançados. Finalmente, em 1983, a Alianza Editorial reeditou todos esses onze volumes anteriores, publicando além disso o último e décimo segundo volume dessas novas Obras Completas. Agora, recentemente, durante 2004 e 2010, a Taurus e a Fundación Ortega y Gasset realizaram um trabalho editorial e de resgate histórico exaustivo reeditando numa bela coleção de dez tomos as Obras Completas de José Ortega y Gasset. 